\title{
HENRY DUNANT INSTITUTE
}

The Assembly of the Henry Dunant Institute met at the Institute on 19 November. As President for the period up to May 1976 it appointed Mr Hans-Peter Tschudi, member of the ICRC and former Federal Councillor, who thus succeeds Mr Jean Pictet, appointed director.

The Assembly took note of the report on the first ten years of the Institute's activities, ${ }^{1}$ published by the Institute on the occasion of the meeting of the Council of Delegates of the International Red Cross, held in Geneva on 24 and 25 September 1975. The Assembly also noted with great satisfaction the resolution adopted unanimously by which the Council expressed its appreciation of the work so far accomplished by the Institute, with slender resources, and requested it to continue its task, at the same time urging the National Societies to collaborate with the Institute, to supply it with all the documentation at their disposal and, as far as they were able, with the funds to enable it to expand its activities.

The Assembly then listened to a report from the new Director on the future outlook, and this gave rise to an interesting discussion. It was considered desirable to widen the Institute's aims and enlarge its scope, in the sense indicated by the Report on the Re-appraisal of the Role of the Red Cross.

Finally, the budget for 1976 was adopted. While this is balanced, for the first time, as far as the Institute itself is concerned, fresh sources of revenue will be necessary if activities are to be further developed and if the Institute is to be capable of providing the improved services expected from it.

\footnotetext{
${ }^{1}$ See International Review No. 175, October 1975.
} 